\title{
Microtubule capture by the cleavage apparatus is required for proper spindle positioning in yeast
}

\author{
Justine Kusch, ${ }^{1}$ Anne Meyer, ${ }^{2}$ Michael P. Snyder, ${ }^{2}$ and Yves Barral ${ }^{1,3}$ \\ ${ }^{1}$ Institute of Biochemistry, Federal Institute of Technology, CH-8092 Zürich, Switzerland; ${ }^{2}$ Department of Molecular, \\ Cellular and Developmental Biology, Yale University, New Haven, Connecticut 06520, USA
}

\begin{abstract}
Cell division is the result of two major cytoskeletal events: partition of the chromatids by the mitotic spindle and cleavage of the cell by the cytokinetic apparatus. Spatial coordination of these events ensures that each daughter cell inherits a nucleus. Here we show that, in budding yeast, capture and shrinkage of astral microtubules at the bud neck is required to position the spindle relative to the cleavage apparatus. Capture required the septins and the microtubule-associated protein Kar9. Like Kar9-defective cells, cells lacking the septin ring failed to position their spindle correctly and showed an increased frequency of nuclear missegregation. Microtubule attachment at the bud neck was followed by shrinkage and a pulling action on the spindle. Enhancement of microtubule shrinkage at the bud neck required the Par-1-related, septin-dependent kinases (SDK) Hsl1 and Gin4. Neither the formin Bnr1 nor the actomyosin contractile ring was required for either microtubule capture or microtubule shrinkage. Together, our results indicate that septins and septin-dependent kinases may coordinate microtubule and actin functions in cell division.
\end{abstract}

[Key Words: Cytokinesis; septin; microtubule; spindle positioning; cell cortex]

Received December 10, 2001; revised version accepted May 5, 2002.

In animal cells, the cleavage apparatus, composed of septins and an actomyosin contractile ring, assembles at the cell cortex during anaphase (Field and Kellogg 1999; Field et al. 1999; Hales et al. 1999|. The plane of this ring defines the plane of cleavage. Proper positioning of the cleavage plane between the two spindle poles ensures the segregation of the replicated chromosomes between the daughter cells. Previous studies showed that spatial coordination of spindle and cleavage apparatus relative to each other depends on astral microtubules and the central spindle (for reviews, see Strome 1993; Gatti et al. 2000).

In budding yeast, the nuclear envelope does not break down during mitosis. The microtubule organizing centers, or spindle pole bodies, are embedded in the nuclear envelope, and the spindle forms inside the nucleus. Spatial coordination of the spindle and the cleavage apparatus is achieved through migration of the nucleus to the bud neck (Shaw et al. 1998; Segal and Bloom 2001). As in animal cells, this coordination event is mediated by astral microtubules (Sullivan and Huffaker 1992; Segal and Bloom 2001). These microtubules, also called cytoplasmic microtubules, are nucleated on the cytoplasmic side of the spindle pole bodies and interact with the cellular cortex with their plus ends. Mutations in tubulin have

${ }^{3}$ Corresponding author.

E-MAIL yves.barral@bc.biol.ethz.ch; FAX 41-(01)-632-1591.

Article and publication are at http://www.genesdev.org/cgi/doi/10.1101/ $\operatorname{gad} .222602$. been isolated that specifically disrupt cytoplasmic but not intranuclear microtubules. These mutations prevent proper positioning of the nucleus (Huffaker et al. 1988; Sullivan and Huffaker 1992) and lead to the formation of binucleated mother cells and anucleated daughters. Much progress has been made in understanding how astral microtubules interact with the cell cortex to move and orient the intranuclear spindle. Two independent pathways mediate these interactions. Early in the cell cycle, the protein Kar9 facilitates microtubule capture at the bud cortex (Adames and Cooper 2000; Yeh et al. 2000). During anaphase, dynein mediates lateral interactions between microtubules and the cellular cortex and helps to pull the daughter nucleus into the bud (Muhua et al. 1994; Cottingham and Hoyt 1997; Adames and Cooper 2000). However, as in animal cells, little is known about how microtubules ensure that the spindle and the cleavage apparatus are properly positioned relative to each other.

The cleavage apparatus has been particularly well characterized in Saccharomyces cerevisiae. Its assembly starts in late $\mathrm{G}_{1}$, simultaneous with bud emergence. First, the septins Cdc3, Cdc10, Cdc11, and Cdc12 form a ring at the bud neck (Longtine et al. 1996). During bud formation, this ring serves as a template for the organization of type II myosin, Myol, into a second ring (Epp and Chant 1997; Bi et al. 1998; Lippincott and Li 1998). This myosin structure is required for the recruitment of actin filaments during mitosis to form the actomyosin 
contractile ring (Bi et al. 1998). Contraction of this ring allows cytokinesis (Bi et al. 1998; Lippincott and $\mathrm{Li}$ 1998). Additional proteins associated with the septin ring include the formin Bnrl (Kikyo et al. 1999), Bni4, a protein involved in the spatial control of chitin synthesis (DeMarini et al. 1997), and the kinases Hsll and Gin4 (Ma et al. 1996; Carroll et al. 1998; Longtine et al. 1998a; Barral et al. 1999). Formins are involved in the nucleation and polymerization of actin filaments (Evangelista et al. 2002; Sagot et al. 2002). Both kinases Hsl1 and Gin4 interact physically with septins, and strictly depend on septin function for localization and activity (Carroll et al. 1998; Longtine et al. 1998a; Barral et al. 1999). For these reasons, we refer to them as septin-dependent-kinases (SDKs). Hsl1, and possibly Gin4, are involved in the control of the $\mathrm{G}_{2} / \mathrm{M}$ transition (Ma et al. 1996; Barral et al. 1999). Remarkably, the closest homologs of SDKs comprise both Nim1 from Schizosaccharomyces pombe (Kanoh and Russell 1998) and the MARK (microtubule affinity regulatory kinase) kinases from higher eukaryotes (Drewes et al. 1998; Barral et al. 1999). MARK kinases control microtubule dynamics in mammals (Drewes et al. 1997, 1998; Ebneth et al. 1999). Caenorhabditis elegans MARK kinase Par-1 (Guo and Kemphues 1995) is involved in spindle positioning. On the basis of this homology, Hsll and Gin4 may also have some function in microtubule-related processes.

In this study, we investigated how the yeast mitotic spindle and cleavage plane are positioned relative to each other. We analyzed whether cells lacking the septin ring or some of its associated components show defects in microtubule organization, nuclear position, and nuclear migration. Our results indicate that the septins, but not the actomyosin ring, are required to form a microtubule capture site at the bud neck-cortex. Upon capture, septin-dependent kinases were required to induce microtubule catastrophe and the creation of a pulling force on the spindle, which then moved toward the bud neck.

\section{Results}

The septin cytoskeleton is required for proper nuclear positioning

In $S$. cerevisiae, the septin ring is necessary for the assembly of all components of the cleavage apparatus identified thus far. Therefore, to determine whether the presence of the cleavage apparatus was necessary for the positioning of the nucleus to the bud neck, we determined whether cells lacking the septin ring positioned their nucleus properly. Two alleles of the CDC12 septin gene were used to disrupt the septin ring. Cells carrying the cdc12-1 temperature-sensitive mutation fail to assemble a ring at the bud neck at restrictive temperatures (Barral et al. 2000). However, cells that have already formed the ring before the shift maintain the ring, finish their cycle, and undergo cytokinesis comparably to wild type (data not shown). In the cdc12-6 allele, the septin ring becomes unstable after shift to the restrictive condition, irrespective of the position of the cell in the division cycle (Barral et al. 2000).
After shift to restrictive temperature $\left(33^{\circ} \mathrm{C}\right)$, a majority of septin-defective cells arrested prior to anaphase failed to localize the nucleus to the bud neck (Fig. 1A,B; $59 \% \pm 9 \%$ of $c d c 12-1$ cells mislocalized their nucleus, $n>1200 ; 57 \% \pm 3 \%$ in $c d c 12-6, n>900)$. This nuclearpositioning defect was quite similar to that observed in cells lacking either Kar9 or dynein (dhc1; Fig. 1B), two proteins that have been implicated in nuclear positioning. The nuclear-positioning defect observed in cells lacking a septin ring suggests that the septin ring may be required either for nuclear migration, or to anchor al-

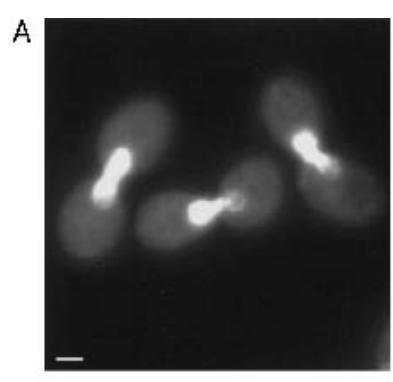

WT

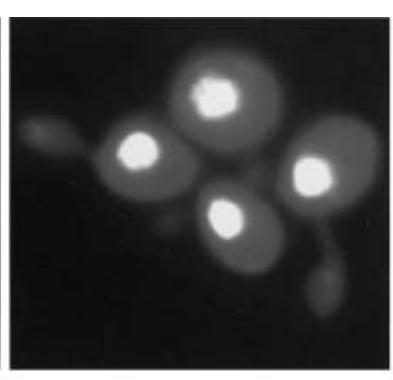

$\operatorname{cdc} 12-1$

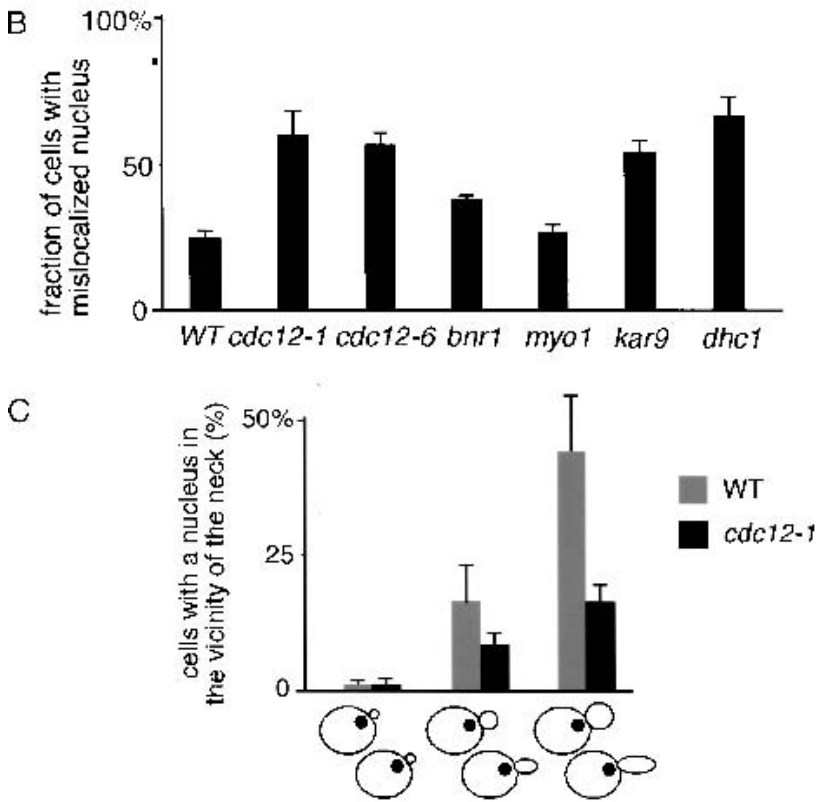

Figure 1. The septin cytoskeleton is involved in the control of nuclear positioning. (A) Micrographs of wild-type (WT) and cdc12-1 mutant cells arrested at the $\mathrm{G}_{2} / \mathrm{M}$ transition with hydroxyurea for $3 \mathrm{~h}$ and stained with DAPI to visualize nuclei. Bar, $2 \mu \mathrm{m}$. (B) Quantification of nuclear-positioning defects in strains mutated for components of the cleavage apparatus. kar9 and $d$ hc 1 mutants are added for comparison. Cells were arrested prior to anaphase, and the frequency of mislocalized nuclei $(\gtrsim 1$ $\mu \mathrm{m}$ away from the bud neck) was determined ( $n \geq 500$ for each strain, in at least two independent counts of 200-300 cells each). (C) Nuclear migration in small- and medium-budded cells of unsynchronized wild-type and $c d c 12-1$ mutant strains. The percentage of cells with a nucleus in the vicinity of the bud neck (within $1 \mu \mathrm{m}$ from the bud neck) is shown. The cells were shifted for $2 \mathrm{~h}$ to the restrictive temperature. 
ready migrated nuclei to the neck region. In the first case, septins may be required as a cortical cue to direct nuclear migration. Septin defects would therefore lead to either random nuclear movements or would impair migration altogether. In contrast, if the septin ring serves to anchor already migrated nuclei, migration should not be affected. The positioning defects should be caused by random movements after the nucleus reached its proper position. To distinguish between these two possibilities, we characterized the effect of septin disruption on early stages of nuclear migration (Fig. 1C). Because nuclear migration happens in parallel to bud growth, most nuclei are generally randomly positioned in small-budded cells, and only a fraction of them has migrated to the bud neck in medium-budded cells. Compared with wild type, small- and medium-budded cells lacking the septin ring showed an even stronger mispositioning of the nucleus (Fig. 1C). Thus, septin function was required for proper nuclear migration.

Nuclear migration defects generally result in a failure of nuclear segregation during mitosis (Huffaker et al. 1988). This leads to the formation of binucleate mothers and anucleate buds. A similar effect is expected if the spindle and the cleavage plane are not correctly positioned relative to each other. Thus, we investigated whether septin mutants have nuclear segregation problems. The cdc12-1 mutant and an isogenic wild-type strain were grown at the restrictive temperature for $3 \mathrm{~h}$, fixed, and stained with DAPI to visualize nuclei; the frequency of binucleate mother cells was then determined. Septin-defective cells showed an increased frequency of binucleated mother cells $(18 \% \pm 10 \%, n=253$ in cdc $12-1$ cells at $\left.33^{\circ} \mathrm{C}\right)$ relative to wild type $(2.8 \% \pm 2.7 \%$, $n=355)$. Altogether these results indicated that septin function is required for proper positioning of the spindle relative to the cleavage plane.

\section{Nuclear-migration defect of septin mutants is not caused by actin-polarity defects}

We recently showed that the septin ring forms a cortical barrier that is required specifically during isotropic bud growth to maintain polarized actin distribution (Barral et al. 2000). During apical growth, the early phase of bud growth, actin polarity does not depend on the presence of the septin barrier (Longtine et al. 1996; Barral et al. 2000). Nevertheless, because actin polarity is required for microtubule orientation and nuclear migration, the nuclear-migration defect observed in septin-defective cells could be caused by actin-polarity defects. Therefore, we examined whether it correlated with actin defects. As shown by the formation of elongated buds (Fig. 1A), cdc12-1 cells did not lose polarity at restrictive temperature and kept growing apically. Rhodamine-phalloidin staining (Fig. 2A) was performed to visualize actin in these cells. No defects in actin polarization and organization were found. Both actin patches and cables polarized normally upon bud emergence, similar to the situation in wild type. Thus, the nuclear positioning defect did not correlate with any lack of actin-polarity.
A

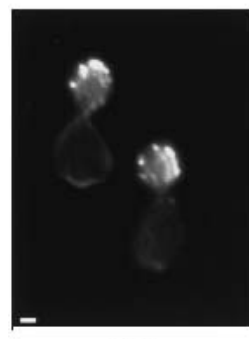

WT

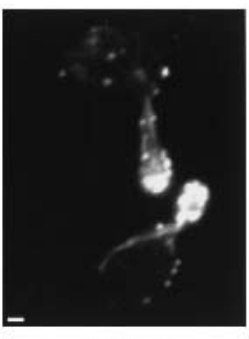

cdc12-1
B

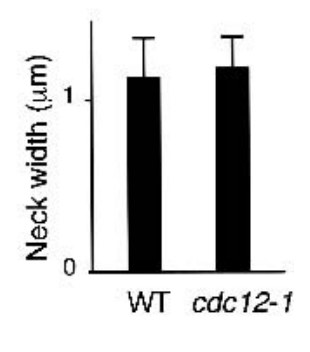

Figure 2. Nuclear-positioning defect in the absence of septin function is not owing to actin or morphological defects. $(A)$ Actin polarity in wild-type and septin-defective cells. Cells grown at the restrictive temperature for $2.5 \mathrm{~h}$ were fixed with formaldehyde and stained with rhodamine-phalloidin. (B) Measurement of the bud neck width in wild-type cells and the cdc12-1 mutant grown at $33^{\circ} \mathrm{C}$ for $3 \mathrm{~h}(n=78$ for wild type and 89 for $c d c 12-1$ ).

The role of actin in nuclear positioning is mediated by Kar9. Kar9 protein interacts with both the type V myosin, Myo2, and the microtubule-associated protein Bim 1 , and thereby mediates interaction between microtubules and cortical actin (Miller et al. 1999; Beach et al. 2000; Yin et al. 2000). Because the main function of actin in nuclear positioning consists in the transport of Kar9 to the bud, we investigated if this process was affected in septin-defective cells. No defect in the localization of Kar9 to and in the orientation of microtubules toward the bud cortex could be observed in cells lacking the septin ring (Fig. 3B,C; see Fig. 6C,D below). Thus, the nuclear-positioning defect observed in the septin mutant was not caused by defects in actin function. Neither was it owing to changes in the width of the bud neck, because this parameter was not significantly affected by the cdc12-1 mutation (Fig. 2B). Therefore, nuclear mispositioning in cells lacking the septin ring was caused by defects in the assembly of the cleavage apparatus, and not by a lack of cell polarity.

\section{Nuclear positioning is independent of the assembly of the actomyosin ring}

To determine whether any neck-specific actin structures are required for nuclear migration, we disrupted $M Y O 1$ and BNR1 individually. Consistent with previous findings (Epp and Chant 1997) indicating that the actomyosin ring is not required for nuclear migration, we found that nuclei localized normally in the myo1 mutant (Fig. 1B). Similarly, elimination of the Bni4 protein, which is required for chitin synthesis, did not affect nuclear positioning (data not shown). Thus, neither the actomyosin contractile ring nor the chitin ring at the bud neck is involved in nuclear positioning.

Cells lacking the bud-neck-specific formin Bnrl showed a mild defect in nuclear positioning (Fig. 1B). Therefore, Bnrl and actin structures dependent on Bnrl may be involved in the septin-dependent positioning of 
Kusch et al.

Figure 3. Astral microtubules establish septin-dependent interactions with the bud neck. (A) Kar9 dots localize at the plus-end of microtubules. Cells expressing Tub1-GFP, Tub1-GFP Kar9-GFP, and Tub1-CFP Kar9-YFP are shown. Both tagged proteins were expressed at endogenous levels. No dot can be seen at the plus-end of microtubules when Kar9 is not tagged with GFP. Double staining shows that these dots correspond to Kar9 dots. Thus, staining of Tub1 and Kar9 both with GFP permits us to visualize microtubule interaction with the cortex. $(B)$ Micrographs of wild-type and mutant cells (genotypes are indicated) expressing GFPTub1 and Kar9-GFP at endogenous levels. The spindle is prominent, and astral microtubules are fainter and emanate from the spindle poles (see drawing in the case of wild type). A Kar9 dot (marked with a red arrow) can be seen at the tip of many astral microtubules. Bar, $1 \mu \mathrm{m} .(C)$ Quantification of microtubule organization in cells with a small spindle. The cells were sorted within three categories (see drawing): (1) no astral microtubule touching either the bud neck or the bud cortex, (2) cells with astral microtubules touching the bud neck cortex, (3) cells with astral microtubules touching the bud cortex. Cells that have astral microtubules touching both the bud neck and the bud cortex were rare $(<3 \%)$ and are excluded from the graph. Results of at least five independent counts per strain, with at least 100 cells per count. $(D)$ Analysis of astral microtubule organization (as in $B$ ) in wild-type and cdc12-1 mutant cells that express only GFP-Tub1. The cdc12-1 and wild-type control cells were shifted to $33^{\circ} \mathrm{C}$ for $3 \mathrm{~h}$.
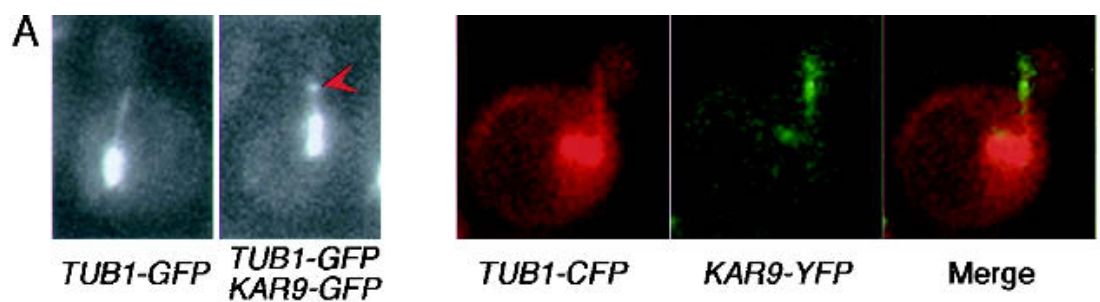

$B$
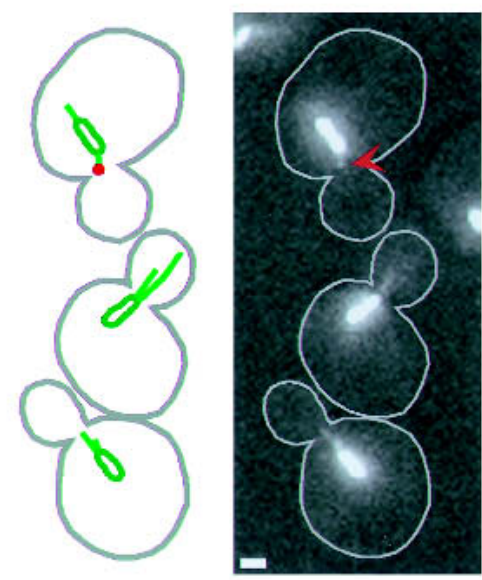

WT

C
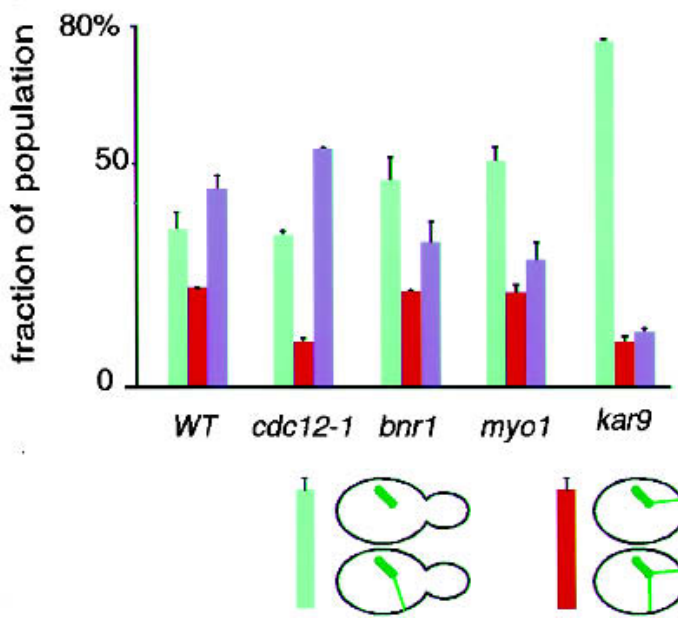

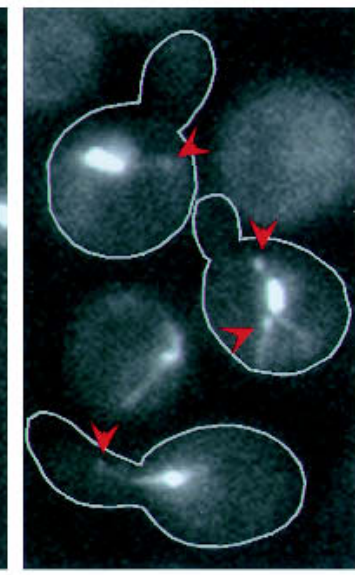

cdc12-1

D
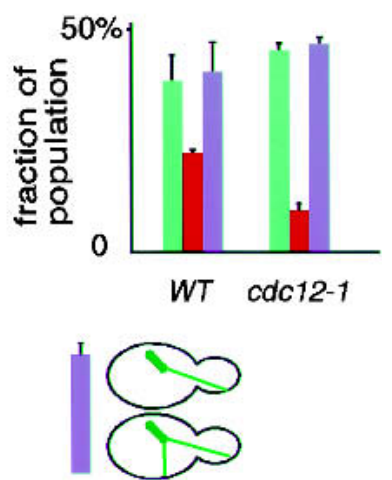

the nucleus. However, because the nuclear-positioning defect is small in the bnr1 strain, such actin structures cannot alone account for the nuclear mispositioning observed in septin-defective cells. Altogether our results indicated that the maintenance of actin polarity, the assembly of the contractile ring, and the role of septins in nuclear migration are three distinct functions of the septin ring.

\section{Microtubules interact with the septin ring}

The movements of the nucleus in the cell depend on the interaction of microtubules with the cell cortex. Therefore, we investigated whether disruption of the septin ring affects the manner with which microtubules interact with the cortex. A GFP-TUB1 reporter construct (Straight et al. 1997) was used to visualize astral microtubules in vivo. In addition, a KAR9-GFP reporter construct was used to visualize contact points between microtubules and the cell cortex. Interestingly, in our experiments Kar9 assembled into dots at the plus end of microtubules (Fig. 3A). To avoid synthetic effects, KAR9-GFP was expressed at endogenous levels for Kar9. Nine $z$-section images through the cell were recorded, and the resulting images were projected using a maximum projection algorithm. This procedure ensured that all cytoplasmic microtubules of the cell could be observed and taken into account. 
In wild-type cells with a short spindle, astral microtubules interacted with the mother, bud neck, and bud cortex (Adames and Cooper 2000; Segal et al. 2000; Vogel and Snyder 2000; Yeh et al. 2000). In yeast, where only a few cytoplasmic microtubules are present, the average distribution of microtubules is highly informative about the stability of the interactions that they establish with the different parts of the cell cortex (see, e.g., Miller et al. 1998). Thus we determined the percentage of cells with microtubules contacting the mother cell, the bud neck, or the bud cortex. This distribution was quite robust, as shown by the low variation observed between independent counts. This suggests that microtubule distribution is the result of tightly regulated processes. Importantly, a substantial number of microtubules $(21 \% \pm 1 \%, n>500)$ interacted with the bud neck with their plus end (Fig. 3A-C; other authors reporting microtubule interaction with the bud neck include Snyder et al. 1991; Segal et al. 2000; Vogel and Snyder 2000; Yeh et al. 2000). This was a high frequency, because the bud neck represents only a small fraction of the overall cell surface. In most cases a Kar9 dot could be unambiguously distinguished at the microtubule end, showing that the microtubule indeed touched the cell cortex at the bud neck. Microtubule interaction with the neck was not caused by fusing GFP to Kar9, because contact was also apparent in the TUB1-GFP KAR9 strain (Fig. 3D). Moreover, replacing Kar9 by Kar9-GFP did not lead to any detectable nuclear-positioning phenotype /data not shown), indicating that Kar9-GFP was fully functional.

In cells lacking the septin ring, the only microtubules that were less frequently observed than in wild type were those contacting the bud neck. In cdc12-1 cells, this category dropped from $20 \% \pm 1 \%$ at the permissive temperature (data not shown) to $9 \% \pm 1 \%, n>500$ at $33^{\circ} \mathrm{C}$, the restrictive temperature. This drop was not owing to difficulties in imaging GFP, because we did not observe any signal loss upon shift to $33^{\circ} \mathrm{C}$. Furthermore, wildtype cells did not show substantial changes in microtubule organization at this temperature (data not shown). The effects observed appeared to be highly significant in regard to the low level of variation observed between experiments. The remaining microtubule-bud-neck interactions observed in $c d c 12-1$ cells most likely reflected random events. This interpretation is supported by the fact that microtubule interaction with the bud neck was reduced to the same level in the kar9 mutant (Fig. 3C). In this mutant, microtubule interaction with the cell cortex prior to anaphase is thought to be random (Miller et al. 1998, 1999). Thus, in wild type, microtubules interacting with the bud neck were transiently captured and/ or stabilized. This led to a clear increase in the number of microtubules interacting with the bud neck, compared with random. The capture and/or stabilization of microtubules at the bud neck required septin function.

Remarkably, septin defects had no negative impact on the interaction of microtubules with other parts of the cell cortex. Particularly, microtubule interaction with the bud cortex was not defective. These results indicate that septins affect microtubule interaction with the cell cortex solely at the bud neck.
In the bnr1 strain, changes in microtubule organization were not observed at the bud neck but at the bud cortex. This suggested that the positioning defect observed in this strain was possibly not caused by defects in the interaction of microtubules with the bud neck. Taken together, our results indicated that astral microtubules established a functional interaction with the bud neck. These interactions depended on septin function, but not on the assembly of actin-related structures. At this point, our data raised the possibility that septindependent interaction of microtubules with the bud neck cortex was required for proper positioning of the nucleus.

\section{Microtubule plus-end capture at the bud neck is associated with the establishment of pulling forces on the spindle}

To investigate how microtubule interaction with the bud neck could be involved in nuclear positioning, we monitored spindle movement upon microtubule attachment to the cortex of wild-type cells. The behavior of microtubules in vivo was recorded by three-dimensional (3D) time-lapse microscopy (Fig. 4A,B). This analysis was carried out in cells expressing both Tub1-GFP and Kar9GFP. Tub1-GFP allowed visualization of microtubules, whereas Kar9-GFP was used as a marker for microtubule/cortex interactions. The tagging of both molecules with the same chromophore allowed very rapid acquisition of image stacks through the cell, without filter changes. With this setup we could monitor microtubule behavior with a very high time resolution. As shown in Figures $3 \mathrm{~A}$ and $4 \mathrm{~A}$, this setup also allowed the clear distinction of Kar9 dots at the plus ends of microtubules. An example of the movies obtained is shown in Figure 4A. In this movie an astral microtubule first grew toward the neck. Upon neck contact, a clearly identifiable Kar9 dot, which may have been faintly present at the tip of the microtubule in the previous frames, formed and gained in intensity. At the same time, the microtubule stopped growing. In the following three frames $(8-10)$ the microtubule shrank and the spindle was pulled for $\sim 0.6 \mu \mathrm{m}$ toward the neck. At frame 11, the spindle stopped moving. Simultaneously, the Kar9 dot faded away, suggesting that the microtubule had detached from the cortex. The duration of this event was $30 \mathrm{sec}$. Altogether, these movies indicated that microtubule capture and shrinkage at the neck permit displacement of the spindle toward the bud neck. Furthermore, these movies indicated that Kar9 was present at the attachment sites at the bud neck and may be functionally involved in the capture process (see below).

To confirm that our observations were not owing to isolated cases, movies of 10 cells and of $15 \mathrm{~min}$ each were analyzed in detail. Contacts between microtubules and the cell cortex were considered established only when a Kar9 dot appeared at the microtubule plus-end. Also, only the cases where only one microtubule could be found contacting the cell cortex at a time were considered. This ensured that the effects observed were not 
Kusch et al.
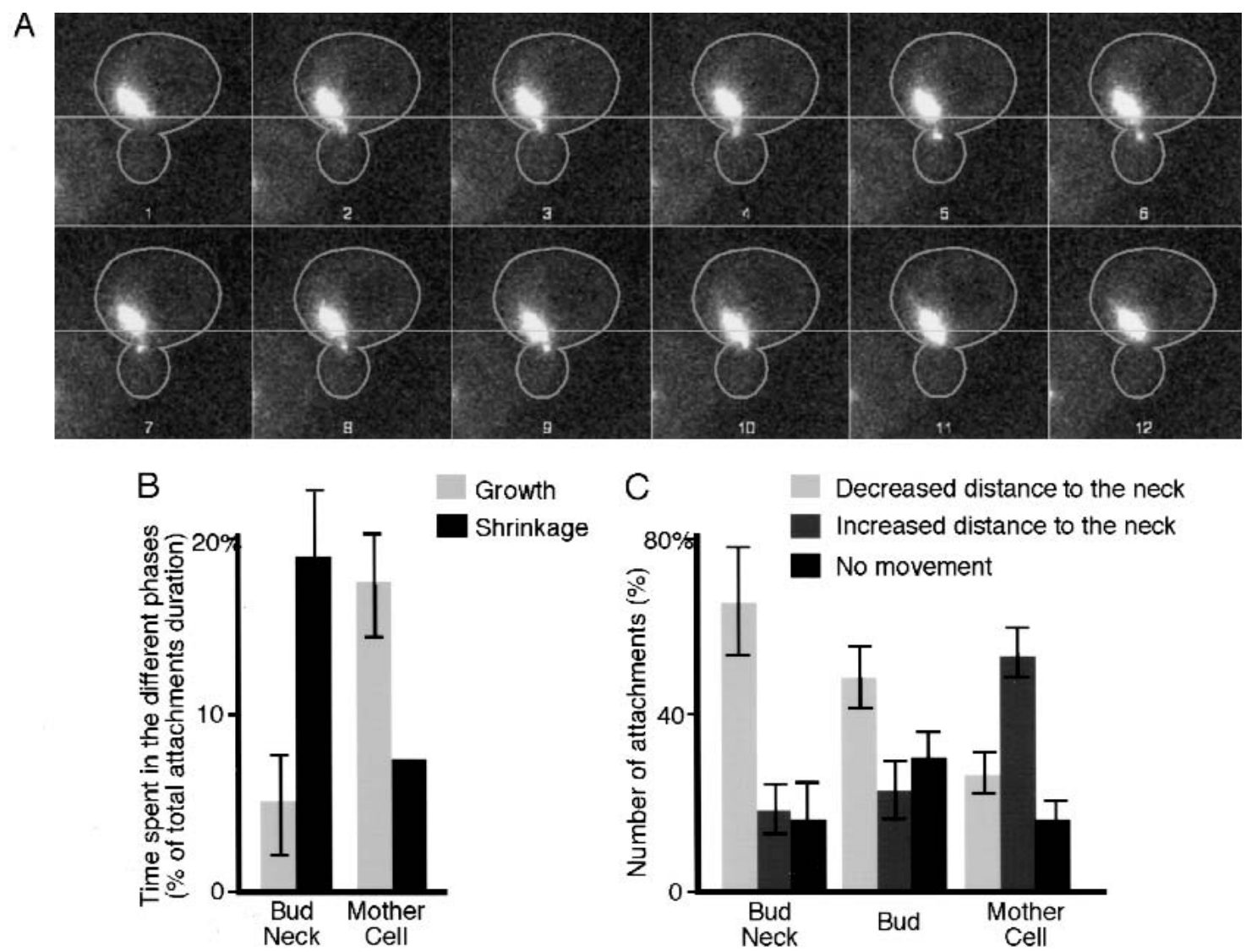

Figure 4. Function of microtubule attachment to the bud neck in nuclear migration. (A) Microtubule capture at the bud neck is associated with shrinkage of the microtubule and pulling of the spindle toward the bud neck. A wild-type cell expressing Kar9-GFP and GFP-Tub1 at endogenous levels is shown. Each frame was generated by projecting images of six focal planes taken through the cell. Frames are taken at 6-sec intervals. The line drawn through all frames marks the position of the spindle at the beginning of the contact event. An astral microtubule grows toward the bud neck (frames 1-6) and remains attached there (defined by the presence of a clear Kar9-GFP dot at the end of the microtubule) during $30 \mathrm{sec}$ (until frame 10). At frames 10-11 it detaches and shrinks back to the spindle pole (frame 11-12). During the second half of the attachment period (frames 6-10), the microtubule shrinks and pulls the spindle toward the bud neck. Bar, $1 \mu \mathrm{m}$. (B) Dynamics of microtubules contacting either the mother or the bud cortex. The fraction of time spent in either growth or shrinkage is shown depending on the cortical domain contacted (mother cell or bud neck). (C) Effect of microtubule attachments on spindle movement, depending on the attachment site. The position of the spindle relative to the bud neck was compared at the beginning and at the end of capture events ( $n=89$ at bud neck, 40 at bud cortex, 43 at mother cortex).

caused by the combination of several contact events. On a total of 150 min of recording, 89 contacts with the bud neck were observed, which had an average duration of $29.5 \mathrm{sec}$. For comparison, in the same cells 43 contacts to the mother cell (average duration $44.5 \mathrm{sec}$ ) and 40 contacts to the bud cortex (average duration $40.6 \mathrm{sec}$ ) were observed. For all the contacts observed, the position of the spindle at the end of the event was compared with its position prior to the contact (Fig. 4C). Contacts with the mother cell cortex led to a displacement of the spindle toward the bud neck in only $26 \%$ of the cases. In contrast, contacts with the bud and bud neck cortex resulted in a movement toward the neck in $48 \%$ and $65 \%$ of the cases, respectively. In the absence of microtubule contacts with the cortex, the spindle did not move. Thus, microtubule interaction with the bud neck led in most cases to nuclear movement toward the bud neck.

To gain more insight into the mechanism of the nuclear movement during cortical contacts, we determined the effects of contacts on microtubule dynamics. The relative duration of microtubule shrinkage and growth was measured during these events (Fig. 4B). Over 26 min of neck contacts (a total of 43 capture events, from 6 different cells), microtubules spent $19.6 \%$ of the time shrinking and $5 \%$ of the time growing. The net result of these contacts was microtubule shrinkage. For comparison, microtubules contacting the mother cortex (30 min total) spent $7.6 \%$ of the time shrinking and $16.7 \%$ of the time growing (Fig. $4 \mathrm{~B}$ ), and the net result of these events was microtubule growth. Thus, microtubule contacts with the bud neck were associated with microtubule shrinkage, leading to a pulling action on the spindle. In contrast, contacts with the mother cortex were associated with microtubule growth, leading to a pushing effect on the spindle. The observation of a pulling action on the spindle upon microtubule interaction 
with the bud neck is strong evidence for microtubule attachment at this site. Thus, our results uncover a new microtubule capture site, the bud neck, and indicate that this capture site is involved in pulling the nucleus toward the neck.

SDKs are required for the shortening of microtubules interacting with the neck

Time-lapse analysis indicated that microtubules behaved differently, depending on whether they contacted the mother or the bud neck cortex. This observation suggested that promoters of microtubule shrinkage might specifically localize to the bud neck. In many cases, microtubule dynamics is regulated through protein phosphorylation events. Moreover, the MARK kinases, to which the septin-dependent kinases Hsll and Gin4 are related (Barral et al. 1999), have been implicated in the stimulation of microtubule shrinkage. Thus, we investigated whether Hsl1 or Gin4 could be implicated in triggering microtubule shrinkage at the bud neck.

First, we analyzed the effect of disrupting HSL1 and GIN4 on microtubule organization. Cells expressing Tub1-GFP and Kar9-GFP were analyzed as in Figure 3B. Two striking phenomena were observed in these cells. (1) The two single mutants hsl1 and gin4 showed an enhanced interaction of microtubules with the bud neck (Fig. 5A,B); $31 \%( \pm 3 \%, n>500)$ of hsl1 cells and $35 \%$ $( \pm 1 \%, n>500)$ of gin4 cells contained microtubules touching the neck region. These effects were additive because the double mutant had an enhanced phenotype $143 \% \pm 2 \%, n>500$ of the hsl1 gin 4 cells showed microtubules connected with the bud neck). (2) In all these strains, the number of microtubules penetrating into the bud decreased proportionally to the increase in microtubules interacting with the bud neck. Two different interpretations could account for these results. On the one hand, it is possible that microtubules interacting with the bud cortex are destabilized in SDK mutants. However, this hypothesis fails to explain why more microtubules would specifically attach to the bud neck. On the other hand, SDK mutations may lead to an excessive stabilization of microtubules binding the bud neck. This would increase the steady-state number of microtubules attached to the bud neck, at the expense of the bud cortex. This last explanation suggests that SDKs activate microtubule dynamics at the bud neck. It has the advantage of being consistent with the localization of Hsll and Gin4.

To test whether increased interaction with the bud neck was accounting for the microtubule organization phenotype of the SDK mutants, we examined the effect of disrupting the septin ring in these cells. Our rationale was that, if SDK mutants led to a stabilization of microtubule/neck interactions, disrupting the septin ring should abolish these interactions. On the other hand, if the SDKs are necessary for microtubule capture at the bud cortex, disrupting the septin ring should have no effect on microtubule interaction with the bud cortex. Our results (Fig. 5B) show that the cdc12-1 hsl1 gin4
A

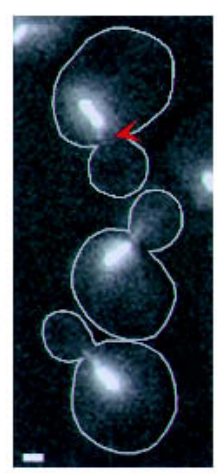

WT

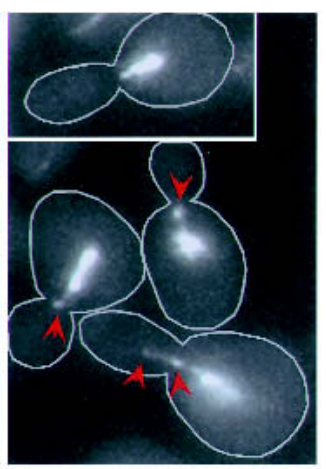

hsil gin4

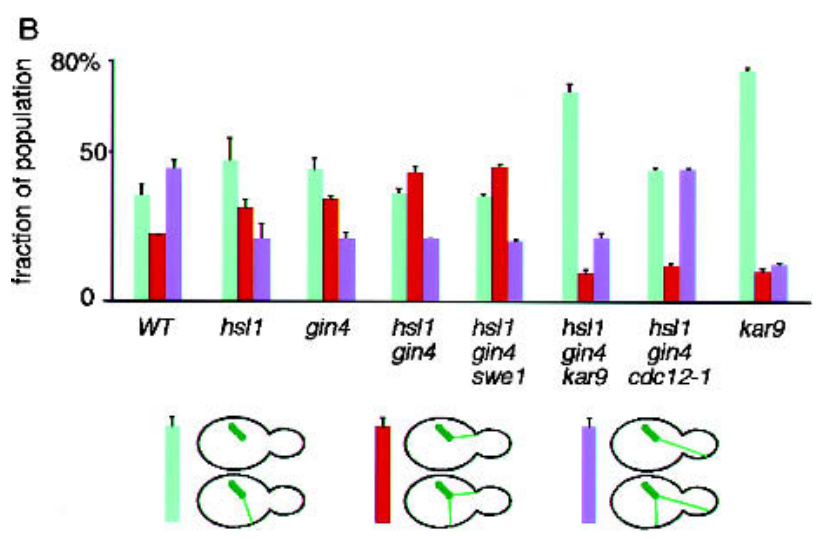

C

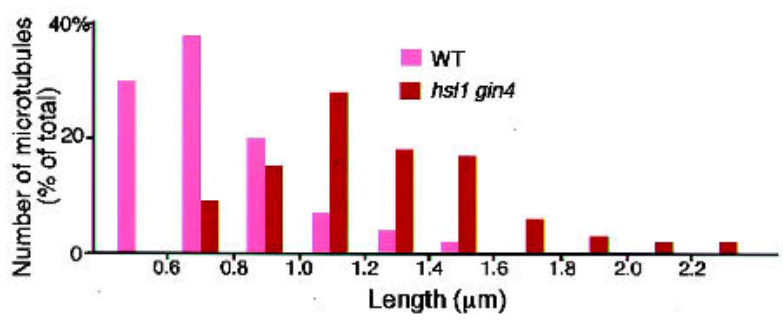

Figure 5. The kinases Hsll and Gin4 are important for proper microtubule dynamics at the bud neck. $(A, B)$ Analysis of microtubule organization in cells lacking Hsll and Gin4 as in Figure $3 \mathrm{~B}$ and $\mathrm{C} .(C)$ Length distribution of microtubules attached at the bud neck in wild-type and in hsl1 gin4 double-mutant cells $(n=56$ in wild type and 64 in the mutant).

cells restored the wild-type level of microtubule interaction with the bud. Consistent with the finding that functional septins are required for microtubule interaction with the bud neck, microtubule binding to the neck was abolished. Thus, cells lacking SDKs develop stable interactions between the microtubules and the bud neck. This stabilization prevents the interaction of microtubules with the bud cortex, indicating that the bud neck and the bud cortex compete for microtubules. Our results therefore suggest that SDKs ensure that microtubule interactions with the bud neck remain dynamic.

Stable microtubules are generally long, whereas dynamic microtubules are shorter. Therefore, to assess whether microtubules interacting with the neck were 
less dynamic in SDK mutants, we analyzed their length. As shown in Figure 5C, microtubules contacting the neck were reproducibly longer in SDK mutants than in wild type (average length in wild type, $0.75 \pm 0.22 \mu \mathrm{m}$; in gin4, $1.14 \pm 0.35 \mu \mathrm{m}$; in $h s 11,1.24 \pm 0.35 \mu \mathrm{m}$; in $h s 11$ gin4, $1.25 \pm 0.48 \mu \mathrm{m})$. Therefore, SDKs are required for the proper regulation of microtubule dynamics at the bud neck. Taken together, our data support the idea that microtubules binding the cleavage apparatus are induced to shrink through SDK-dependent phosphorylation events.

Disruption of HSL1 and GIN4 lead to a $\mathrm{G}_{2}$ delay, which is abolished by disruption of the SWE1 gene (Barral et al. 1999). The stabilization of microtubule/neck interactions in SDK mutants may be owing to these cells spending more time in $\mathrm{G}_{2}$. To test this possibility, we analyzed microtubule organization in the hsl1 gin4 swe1 triple mutant. Disruption of SWE1 suppressed the cell cycle progression defects observed in hsl1, gin4, and hsl1 gin4 mutants (see Materials and Methods; Barral et al. 1999|. However, it did not suppress the enhanced microtubule interaction phenotype (Fig. 5B). Thus, the role of Hsll and Gin4 in the regulation of microtubule/neck interaction was independent of their function in cell cycle control and not mediated by Swe1. Therefore, the effect of SDKs on microtubule dynamics at the bud neck is most likely direct.

\section{Septins act in the Kar9 pathway}

Because Kar9 was found to be present at microtubule attachment sites at the bud neck, we investigated the functional relevance of this presence. In yeast, nuclear positioning is ensured by two redundant pathways (Cottingham and Hoyt 1997; DeZwaan et al. 1997; Miller and Rose 1998; Miller et al. 1998; Adames and Cooper 2000; Yeh et al. 2000). The Kar9 pathway acts early during bud formation. It positions the spindle to the bud neck, aligned along the mother-bud axis (Adames and Cooper 2000; Yeh et al. 2000). In cells lacking Kar9, spindle positioning is very inefficient (see Fig. 1) and depends on the function of dynein (encoded by the DHC1 gene), a microtubule-dependent motor (Muhua et al. 1994; Cottingham and Hoyt 1997; Adames and Cooper 2000). Accordingly, dynein mutants also have a nuclear-positioning defect (Fig. 1B). Although mutants affecting either the Kar9 or the dynein pathway are viable, inactivation of both pathways is lethal (Cottingham and Hoyt 1997; DeZwaan et al. 1997; Miller and Rose 1998). Nuclei divide in the mother cell at mitosis and fail to become segregated, leading to the formation of binucleate mother cells and anucleate daughters.

We determined genetically if septins acted either in the Kar9 or in the dynein pathway. At the semipermissive temperature of $30^{\circ} \mathrm{C}$, the cdc12-1 strain grew slowly (Fig. 6A) and showed septin organization defects (data not shown). At the same temperature cdc12-1 dhc1, cdc12-1 num1, and cdc12-1 bik1 cells were unable to do more than a few divisions (Fig. 6A, Num1 and Bik1 act in the dynein pathway; Pellman et al. 1995; Farkasovsky and Kuntzel 2001). Analysis of the cdc12-1 dhc1 cells showed that the mother cells rapidly became multinucleated (data not shown). Thus, these cells were strongly defective for nuclear segregation. In contrast, the cdc12-1 kar9 and cdc12-1 kip3 strains grew as well as the cdc12-1 single mutant (Fig. 6A, Kip3 acts in the Kar9 pathway; Cottingham and Hoyt 1997; DeZwaan et al. 1997). At permissive temperature, all six strains grew at rates very similar to wild type. Thus, in septin-defective cells the Kar9 pathway is deficient and unable to compensate for the loss of dynein. In contrast, in $c d c 12-1$ kar9 and cdc12-1 kip3 cells, dynein can compensate for the loss of the Kar9 pathway, indicating that the dynein pathway does not require septins for function. Septins therefore act in the Kar9 pathway but not in the dynein pathway.

\section{Kar9 links microtubules to the septin ring}

The observation that septins act in the Kar9 pathway suggested that microtubule capture at the bud neck may depend on Kar9. We therefore reinvestigated the localization of Kar9 using a Kar9-GFP fusion protein expressed from the endogenous KAR9 promoter (Fig. 6B). To eliminate Kar9 dots at the spindle poles from our counts, we quantified Kar9 localization in cells in which both Tub1 and Kar9 were stained. Only Kar9 dots that are at the plus-end of microtubules and Kar9 dots that are not associated with microtubules $(<0.5 \%)$ were counted. This study indicated that Kar9 localized frequently to the bud neck (similarly to Beach et al. 2000); $37 \% \pm 1 \%(n=140)$ of $\operatorname{Kar} 9$ dots localized to the bud neck, $35 \%( \pm 1 \%, n=140)$ to the bud cortex (Fig. 6C). Consistent with the microtubule distribution results, Kar9 localization to the bud neck in cdc12-1 cells was reduced to $15 \%( \pm 0 \%, n=268)$ at restrictive temperature (Fig. 6C). In this study, it was never possible to find Kar9 dots at the bud neck independently of microtubules. This result was consistent with time-lapse microscopy data showing that the Kar9 dot formed upon microtubule attachment. Thus, both septins and microtubules were necessary to recruit Kar9 at the bud neck. This may be different from the situation reported for microtubule capture at the bud tip, where Kar9 dots were found independently of microtubule capture (Miller and Rose 1998; Miller et al. 1998, 1999; Beach et al. 2000).

In any case, our results suggested that Kar9 might facilitate microtubule capture by the cleavage apparatus. To test this possibility, we analyzed microtubule organization in cells lacking Kar9. Deletion of KAR9 strongly reduced the frequency of microtubules interacting with the bud neck in both wild type and the hsl1 gin4 double mutants (Fig. 5B). In contrast, no reduction in microtubule interaction with the bud neck was observed in the dhc1 strain compared with wild type (data not shown). Therefore, our genetic and microscopy data both indicated that Kar9, and not dynein, mediated the capture of astral microtubules by the cleavage apparatus. 
A
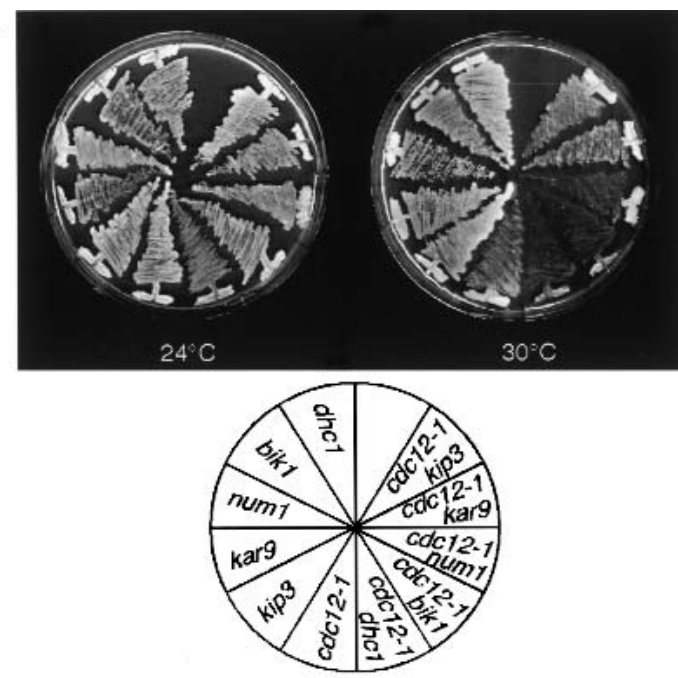

B

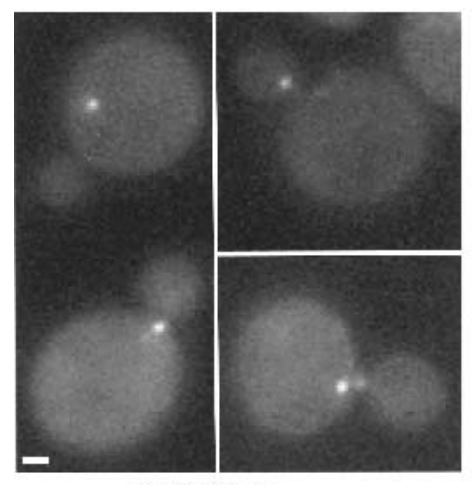

Kar9-GFP

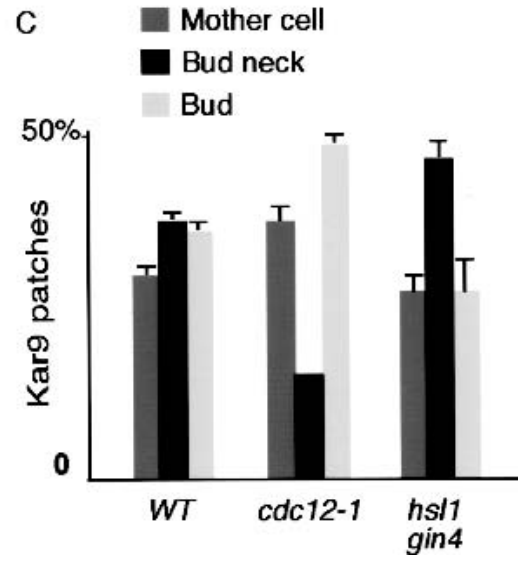

Figure 6. Role of septins in Kar9 function and localization. (A) Genetic interactions between $c d c 12-1$ and mutations in genes participating in either the Dhcl (dhc1, bik1, num1) or the Kar9 pathways (kar9, kip3) for nuclear migration. Strains of indicated genotypes were streaked out on the same plates and were incubated at either $24^{\circ} \mathrm{C}$ or $30^{\circ} \mathrm{C}$ for $3 \mathrm{~d}$. See Materials and Methods for the construction of the strains. (B) Micrographs of wild-type cells expressing Kar9-GFP under the endogenous promoter. The two upper cells show Kar9 in the mother cell and at the cortex of the bud. The two lower cells have one dot each at the bud neck. Bar, $1 \mu \mathrm{m}$. $(C)$ Quantification of Kar9 distribution to the mother cell, bud neck, and bud cortex in wildtype cells, cdc12-1 mutants, and gin4 hsl1 double mutants. Quantification was made in cells stained for both tubulin and Kar9. Only the Kar9 dots associated with microtubule distal tips and the cortex were counted ( $n=140$ for WT, 268 for $c d c 12-1,110$ for hsl1 gin4; average of at least two independent counts).

\section{Septins are not involved in spindle alignment}

Prior to mitosis, the spindle does not only need to be positioned at the bud neck but also to be aligned along, that is, parallel to, the mother bud axis. Kar9 has been shown to act in both spindle positioning and spindle alignment. Disruption of $B N I 1$, which is required for Kar9 localization to the bud cortex (Lee et al. 1999; Miller et al. 1999), affects spindle alignment (Fig. 7A). In contrast, we found that spindle alignment was not defective in cells lacking the septin ring (Fig. 7A). Thus, the septin ring is specifically involved in spindle positioning to the bud neck and not in its alignment along the mother/bud axis.

\section{Discussion}

In this study, we show the existence of a new microtubule capture site at the yeast bud neck. Microtubule shrinkage and a pulling action on the spindle toward the bud neck followed microtubule capture at this site. This capture site was no longer present in cells lacking the septin ring, indicating that septins or other downstream components of the cleavage apparatus were required for microtubule capture. These capture events were functionally important because septin mutants showed nuclear-positioning and nuclear-segregation defects at restrictive temperatures. These defects did not correlate with actin defects, but only with a decrease of microtubule interaction with the bud neck. Therefore, microtubule capture at the bud neck was required for proper positioning of the nucleus. We propose that microtubule capture and shrinkage at the bud neck are required to pull the nucleus toward the cleavage apparatus.

Disruption of the actomyosin ring and the formin Bnrl did not lead to microtubule capture defects. Because these mutations are thought to disrupt bud-neck-specific actin structures, our results suggest that actin may not be required for microtubule capture at the bud neck. This is different from what has been reported for microtubule capture at the bud tip. Disruption of other septinassociated proteins such as Bni4, Hsl1, and Gin4 also did not abolish microtubule interaction with the septin ring. Therefore, the protein(s) mediating microtubule interaction with the cleavage apparatus still remain to be identified. One attractive possibility is that such proteins are the septins themselves. In support of this idea, Drosophila septins Pnut, Sep1, and Sep2 have been reported 
Kusch et al.
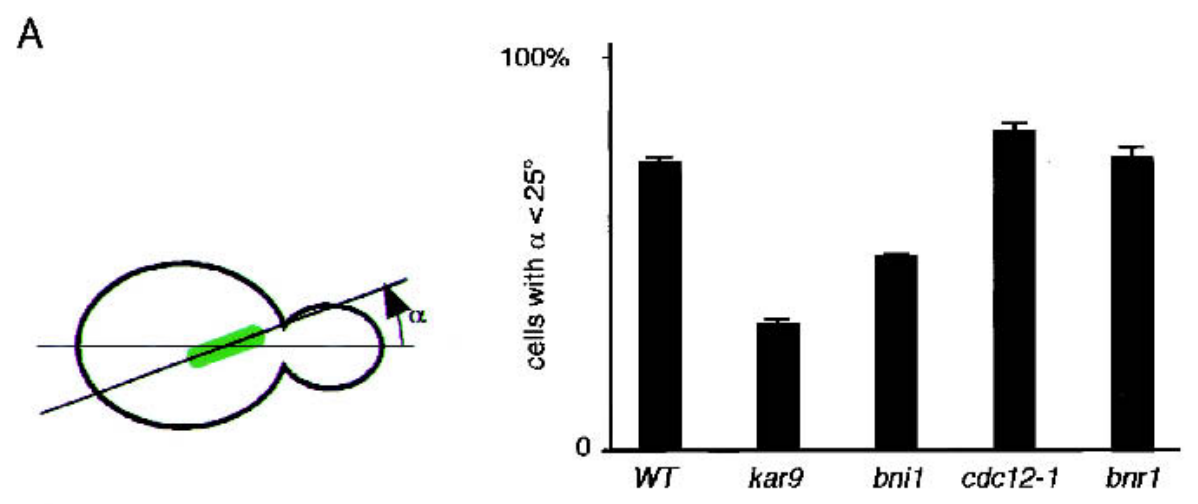

B

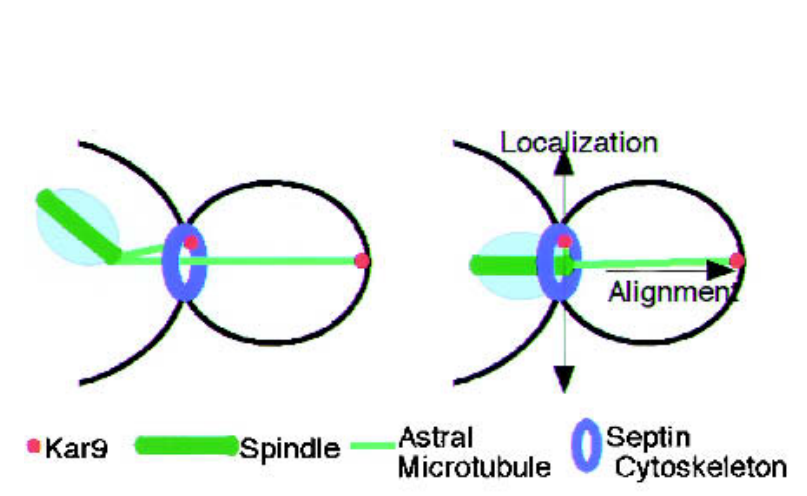

C

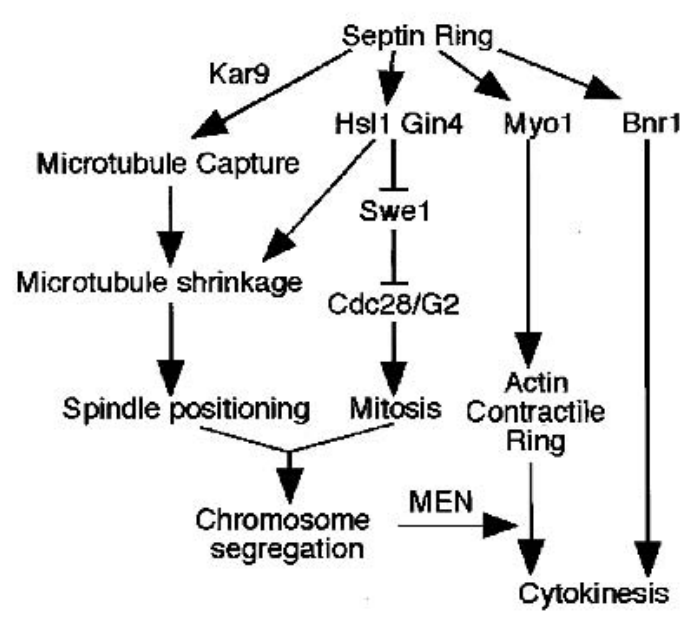

Figure 7. Role of the septins in coordination of cytoplasmic and nuclear events in cell division. (A) Role of the septins in spindle alignment. Unlike kar9 and bni1 mutants, cells lacking the septin ring are fully competent for spindle alignment. Deletion of the formin BNR1 has no effect. Results of at least two counts with a minimum of 80 cells per count. $(B)$ Model: Astral microtubule interaction with the septin-dependent cytoskeleton participates in bringing the nucleus to the bud neck. The dynamics of microtubules at the bud neck is regulated by SDK Hsll and Gin4. Spindle alignment occurs through microtubule interaction with the bud cortex. Both processes are Kar9-dependent. $(C)$ Model: The septins are involved in at least three independent processes: the recruitment of Bnrl and Myo1, which are required for cytokinesis; the recruitment and activation of Hsl1 and Gin4; and the Kar9-dependent capture of microtubules. In turn, Hsl1 and Gin4 regulate both entry into mitosis (via repression of Swe1) and microtubule dynamics at the bud neck. Microtubule capture and shrinkage are required to position the spindle relative to the cleavage apparatus. After proper anaphase (chromosome segregation), the mitotic exit network (MEN) induces cytokinesis.

to bind onto microtubule columns (Sisson et al. 2000). Thus, it will be important to determine whether septins can interact directly with Kar9 and/or microtubules.

Altogether, our results are consistent with the model presented in Figure 7B. In yeast, spindle positioning depends on two processes: the alignment of the spindle along the mother-bud axis and the positioning of the nucleus relative to the cleavage apparatus. The Kar9 pathway is involved in both processes. We suggest that it fulfills these functions by interacting with two distinct cortical structures, respectively, the bud cortex and the cleavage apparatus at the bud neck. Our results also implicate dynein in nuclear positioning independently of its role in spindle alignment. If dynein were only acting through its role in spindle alignment, it should not be colethal with septin defects, because in these cells Kar9 is still able to orient the spindle properly. Dynein may therefore have an additional role in nuclear positioning independent of its role in spindle alignment. As presented in Figure 7C, we propose that septin plays a pivotal role in cell division: it serves as a linker to organize and position actin- and microtubule-related structures relative to each other.

Microtubule capture at the bud neck was associated with microtubule shrinkage. In cells lacking SDKs, microtubules remained attached to the bud neck for longer periods of time and were increased in length. From these experiments, we propose that the regulation of microtubule dynamics upon capture at the bud neck is ensured by MARK-related septin-dependent kinases.

The involvement of SDKs in nuclear positioning is a remarkable result, because it indicates that, at least in yeast, the same kinases coordinate nuclear and cortical events of mitosis at both the temporal level, through regulation of Swe1 (Barral et al. 1999), and at the spatial levels, through regulation of microtubule function (Fig. 
7C). This coregulation of entry into mitosis and spatial coordination of spindle and cleavage apparatus may be conserved, at least in $S$. pombe. Indeed, in this organism, the kinase Cdr2, the homolog of S. cerevisiae Gin4, influences both the timing of mitosis (Breeding et al. 1998; Kanoh and Russell 1998) and the positioning of the cleavage apparatus (Breeding et al. 1998). Thus, Cdr2 may regulate a microtubule-dependent event involved in the positioning of the cleavage apparatus in fission yeast. In summary, our results provide the first evidence that Par-1-like molecules control microtubule function also in yeast. This finding will open new possibilities to determine how this class of kinases controls microtubule function.

Septins and septin-dependent kinases are highly conserved in animal cells. Therefore, it is tempting to speculate that interactions between astral microtubules and the septin cytoskeleton may be conserved and spatially coordinate the spindle and the cleavage machinery in higher eukaryotes. Astral microtubules and microtubules from the central spindle may bind to septin-dependent structures of animal cells. Such microtubules may thereby recruit septins to the equator of the cell to position the cleavage apparatus properly relative to the spindle.

\section{Materials and methods}

\section{Quantification of nuclear migration}

Nuclear migration was assayed as described (Yeh et al. 1995). Briefly, log phase cultures of the indicated strains were diluted in fresh complete medium in the presence of $100 \mathrm{mM}$ hydroxyurea. After $2.5 \mathrm{~h}$ at room temperature $\left(22-24^{\circ} \mathrm{C}\right),>85 \%$ of the cells were arrested with a large bud and a single nucleus. The cells were fixed with $70 \%$ ethanol for at least $0.5 \mathrm{~h}$. After washing the cells in PBS, nuclei were stained with DAPI and viewed using an Olympus fluorescence microscope. Nuclei that were $>1 \mu \mathrm{m}$ away from the bud neck were considered as mislocalized. In the case of septin mutants, the cells were shifted to the minimal restrictive temperature $\left(30^{\circ} \mathrm{C}\right.$ for $c d c 12-6$ and $33^{\circ} \mathrm{C}$ for $c d c 12-1)$ directly after being put in the presence of hydroxyurea. In the ideal case the experiment should be done by shifting the cells back to the permissive conditions to determine whether nuclear positioning was restored. However, the septin defect was not reversible, preventing this approach. Shifting the nontemperature-sensitive strains (such as the wild type and the hsl1 and gin 4 mutants) to these temperatures did not significantly affect nuclear localization compared with room temperature (data not shown). For nuclear migration analysis in unsynchronized populations, cells were grown in YPD at room temperature until early log phase and subsequently shifted to $33^{\circ} \mathrm{C}$ for 3 $\mathrm{h}$ before fixation. (At this time all cells had failed to assemble a septin ring, as indicated by apically growing buds and cytokinetic defects.) The fraction of cells with the nucleus within 1 $\mu \mathrm{m}$ from the bud neck was counted in cells with small, medium, or large buds.

To determine whether septin-defective cells showed defects in nuclear segregation, we grew $c d c 12-1$ cells at restrictive temperatures for $3 \mathrm{~h}$, fixed the cells, and stained with DAPI to visualize nuclei. During this period, the cells did not progress through more than one cycle. Therefore, a change in the fre- quency of binucleated mother cells following the shift to restrictive temperature reflects the frequency of nuclear missegregation per cell cycle.

\section{Strains and growth conditions}

All strains were grown in rich medium (YPD) at room temperature, unless indicated otherwise. Gene disruption and GFP tagging was achieved using a PCR-derived approach as described (Longtine et al. 1998b). The transformants were subsequently screened by PCR, microscopy, and phenotypic analysis. Deletion of SWE1 in hsl1, gin4, and hsl1 gin4 mutants suppressed the accumulation of premitotic cells as quantified by the frequency of cells with short spindles and large budded cells with a single nucleus. It also suppressed the formation of elongated cells characteristic of these strains owing to prolonged apical bud growth (Barral et al. 1999). Production of the multiple mutant strain was systematically achieved through crossings. In the case of the $c d c 12-1$ kip3 strain, 25 full tetrads were obtained, producing $26 c d c 12-1$ KIP3 spores and 24 cdc12-1 kip3 spores. All spores were tested for growth at $30^{\circ} \mathrm{C}$, and no growth difference was observed between $c d c 12-1$ and $c d c 12-1$ kip3 strains. Twenty $c d c 12-1$ and $18 c d c 12-1$ bik1 strains were obtained out of 19 full tetrads. At $30^{\circ} \mathrm{C}$, none of the $c d c 12-1$ bik1 spores grew. Sixteen $c d c 12-1$ and $12 c d c 12-1$ num 1 spores were obtained out of 14 full tetrads; all double mutants died at $30^{\circ} \mathrm{C}$. Finally, 26 $c d c 12-1 d h c 1$ and a similar number of independent $c d c 12-1$ kar9 spores were obtained. In $100 \%$ of the cases, the $c d c 12-1$ dhc1 spores died at $30^{\circ} \mathrm{C}$, but the $c d c 12-1$ kar9 strains grew. In all these experiments, $c d c 12-1$ spores also grew at $30^{\circ} \mathrm{C}$.

\section{Fluorescence and time-lapse microscopy}

Cells were mounted in low autofluorescence selective drop-in medium shortly before viewing. Objects were subjected to timelapse microscopy for a maximum of $15 \mathrm{~min}$.

To visualize GFP-labeled microtubules and quantify their organization in vivo, full-frame pictures of fields of cells were taken at 9 focal planes $(0.2 \mu \mathrm{m}$ step size) using an Olympus BX50 fluorescence microscope, a piezo motor, and the TILLVision software (TILLphotonics, Martinsried, Germany). The pictures were projected on one single plane using the maximum method. When Kar9-GFP was overexpressed from the GAL promoter, Kar9 dots were more frequently observed at the bud tip, indicating that Kar9 overexpression may affect its localization. For analysis of Kar9 distribution and microtubule organization in $c d c 12-1$ ts-mutants, the cells were shifted to restrictive temperature $\left(33^{\circ} \mathrm{C}\right)$ for $3 \mathrm{~h}$ before microscopy.

To investigate microtubule attachments, growth/shrinkage, and spindle movements, Z-stacks of 6 focal planes $(0.3 \mu \mathrm{m}$ step size) were taken at intervals of $6 \mathrm{sec}$ for a total time of $15 \mathrm{~min}$. Z-stacks were projected by the maximum method. Before each movie a single transmission image was taken at the middle focal plane.

For analysis of microtubule length and dynamics, spindle pole body movement respective to the neck, and timing of microtubule attachments, we used NIH Image 1.62b7 (Wayne Rasband, $\mathrm{NIH}$ ). Microtubules were regarded as attached when Kar9-GFP dots were visible at the microtubule tips. Transmission images served to confirm microtubule attachments at bud neck, mother cortex, or bud cortex. Coordinate values of the proximal spindle pole body at the beginning and at the end of the attachments were recorded to determine whether the spindle moved toward or away from the bud neck. Attachments could last from $6 \mathrm{sec}$ to $3.5 \mathrm{~min}$ and could consist of different types of micro- 
tubule end behavior including slight movements like gliding or sweeping and still capture at a single site.

\section{Acknowledgments}

We thank J. Vogel and C. Mann for providing strains and constructs. We also thank Markus Aebi, A. Helenius, and the members of the Barral laboratory for support and discussions; and $\mathrm{M}$. Bornens, R. Kroschewski, D. Liakopoulos, A. Paoletti, and M. Peter for their comments on the manuscript. We are indebted to R. Moser and A. Lehman for their technical support during many phases of this work. M.P.S. is supported by a grant from the NIH. J.K. and Y.B. are supported by the Swiss Federal Institute of Technology.

The publication costs of this article were defrayed in part by payment of page charges. This article must therefore be hereby marked "advertisement" in accordance with 18 USC section 1734 solely to indicate this fact.

\section{References}

Adames, N.R. and Cooper, J.A. 2000. Microtubule interactions with the cell cortex causing nuclear movements in Saccharomyces cerevisiae. J. Cell Biol. 149: 863-874.

Barral, Y., Parra, M., Bidlingmaier, S., and Snyder, M. 1999. Nim1-related kinases coordinate cell cycle progression with the organization of the peripheral cytoskeleton in yeast. Genes \& Dev. 13: 176-187.

Barral, Y., Mermall, V., Mooseker, M.S., and Snyder, M. 2000. Compartmentalization of the cell cortex by septins is required for maintenance of cell polarity in yeast. Mol. Cell 5: 841-851.

Beach, D.L., Thibodeaux, J., Maddox, P., Yeh, E., and Bloom, K. 2000. The role of the proteins Kar9 and Myo2 in orienting the mitotic spindle of budding yeast. Curr. Biol. 10: 14971506.

Bi, E., Maddox, P., Lew, D.J., Salmon, E.D., McMillan, J.N., Yeh, E., and Pringle, J.R. 1998. Involvement of an actomyosin contractile ring in Saccharomyces cerevisiae cytokinesis. J. Cell Biol. 142: 1301-1312.

Breeding, C.S., Hudson, J., Balasubramanian, M.K., Hemmingsen, S.M., Young, P.G., and Gould, K.L. 1998. The cdr2(+) gene encodes a regulator of $\mathrm{G} 2 / \mathrm{M}$ progression and cytokinesis in Schizosaccharomyces pombe. Mol. Biol. Cell 9: 33993415.

Carroll, C.W., Altman, R., Schieltz, D., Yates, J.R., and Kellogg, D. 1998. The septins are required for the mitosis-specific activation of the Gin4 kinase. J. Cell Biol. 143: 709-717.

Cottingham, F.R. and Hoyt, M.A. 1997. Mitotic spindle positioning in Saccharomyces cerevisiae is accomplished by antagonistically acting microtubule motor proteins. I. Cell Biol. 138: 1041-1053.

DeMarini, D.J., Adams, A.E., Fares, H., De Virgilio, C., Valle, G., Chuang, J.S., and Pringle, J.R. 1997. A septin-based hierarchy of proteins required for localized deposition of chitin in the Saccharomyces cerevisiae cell wall. J. Cell Biol. 139: 75-93.

DeZwaan, T.M., Ellingson, E., Pellman, D., and Roof, D.M. 1997. Kinesin-related KIP3 of Saccharomyces cerevisiae is required for a distinct step in nuclear migration. J. Cell Biol. 138: 1023-1040.

Drewes, G., Ebneth, A., Preuss, U., Mandelkow, E.M., and Mandelkow, E. 1997. MARK, a novel family of protein kinases that phosphorylate microtubule- associated proteins and trigger microtubule disruption. Cell 89: 297-308.
Drewes, G., Ebneth, A., and Mandelkow, E.M. 1998. MAPs, MARKs and microtubule dynamics. Trends Biochem. Sci. 23: 307-311.

Ebneth, A., Drewes, G., and Mandelkow, E. 1999. Phosphorylation of MAP2c and MAP4 by MARK kinases leads to the destabilization of microtubules in cells. Cell Motil. Cytoskeleton 44: 209-224.

Epp, J.A. and Chant, J. 1997. An IQGAP-related protein controls actin-ring formation and cytokinesis in yeast. Curr. Biol. 7: 921-929.

Evangelista, M., Pruyne, D., Amberg, D.C., Boone, C., and Bretscher, A. 2002. Formins direct Arp2/3-independent actin filament assembly to polarize cell growth in yeast. Nat. Cell Biol. 4: 32-41.

Farkasovsky, M. and Kuntzel, H. 2001. Cortical Num1p interacts with the dynein intermediate chain Pac1lp and cytoplasmic microtubules in budding yeast. J. Cell Biol. 152: $251-262$.

Field, C.M. and Kellogg, D. 1999. Septins: Cytoskeletal polymers or signaling GTPases? Trends Cell Biol. 9: 387-394.

Field, C., Li, R., and Oegema, K. 1999. Cytokinesis in eukaryotes: A mechanistic comparison. Curr. Opin. Cell Biol. 11: $68-80$.

Gatti, M., Giansanti, M.G., and Bonaccorsi, S. 2000. Relationships between the central spindle and the contractile ring during cytokinesis in animal cells. Microsc. Res. Tech. 49: 202-208.

Guo, S. and Kemphues, K.J. 1995. par-1, a gene required for establishing polarity in C. elegans embryos, encodes a putative Ser/Thr kinase that is asymmetrically distributed. Cell 81: 611-620.

Hales, K.G., Bi, E., Wu, J.Q., Adam, J.C., Yu, I.C., and Pringle, J.R. 1999. Cytokinesis: An emerging unified theory for eukaryotes? Curr. Opin. Cell Biol. 11: 717-725.

Huffaker, T.C., Thomas, J.H., and Botstein, D. 1988. Diverse effects of $\beta$-tubulin mutations on microtubule formation and function. J. Cell Biol. 106: 1997-2010.

Kanoh, J. and Russell, P. 1998. The protein kinase Cdr2, related to Nim1/Cdr1 mitotic inducer, regulates the onset of mitosis in fission yeast. Mol. Biol. Cell 9: 3321-3334.

Kikyo, M., Tanaka, K., Kamei, T., Ozaki, K., Fujiwara, T., Inoue, E., Takita, Y., Ohya, Y., and Takai, Y. 1999. An FH domaincontaining Bnrlp is a multifunctional protein interacting with a variety of cytoskeletal proteins in Saccharomyces cerevisiae. Oncogene 18: 7046-7054.

Lee, L., Klee, S.K., Evangelista, M., Boone, C., and Pellman, D. 1999. Control of mitotic spindle position by the Saccharomyces cerevisiae formin Bnilp. J. Cell Biol. 144: 947-961.

Lippincott, J. and Li, R. 1998. Sequential assembly of myosin II, an IQGAP-like protein, and filamentous actin to a ring structure involved in budding yeast cytokinesis. J. Cell Biol. 140: 355-366.

Longtine, M.S., DeMarini, D.J., Valencik, M.L., Al-Awar, O.S., Fares, H., De Virgilio, C., and Pringle, J.R. 1996. The septins: Roles in cytokinesis and other processes. Curr. Opin. Cell Biol. 8: 106-119.

Longtine, M.S., Fares, H., and Pringle, J.R. 1998a. Role of the yeast Gin $4 p$ protein kinase in septin assembly and the relationship between septin assembly and septin function. $J$. Cell Biol. 143: 719-736.

Longtine, M.S., McKenzie III, A., Demarini, D.J., Shah, N.G., Wach, A., Brachat, A., Philippsen, P., and Pringle, J.R. 1998b. Additional modules for versatile and economical PCR-based gene deletion and modification in Saccharomyces cerevisiae. Yeast 14: 953-961.

Ma, X.J., Lu, Q., and Grunstein, M. 1996. A search for proteins 
that interact genetically with histone $\mathrm{H} 3$ and $\mathrm{H} 4$ amino termini uncovers novel regulators of the Swel kinase in Saccharomyces cerevisiae. Genes \& Dev. 10: 1327-1340.

Miller, R.K. and Rose, M.D. 1998. Kar9p is a novel cortical protein required for cytoplasmic microtubule orientation in yeast. J. Cell Biol. 140: 377-390.

Miller, R.K., Heller, K.K., Frisen, L., Wallack, D.L., Loayza, D., Gammie, A.E., and Rose, M.D. 1998. The kinesin-related proteins, Kip2p and Kip3p, function differently in nuclear migration in yeast. Mol. Biol. Cell 9: 2051-2068.

Miller, R.K., Matheos, D., and Rose, M.D. 1999. The cortical localization of the microtubule orientation protein, Kar9p, is dependent upon actin and proteins required for polarization. J. Cell Biol. 144: 963-975.

Muhua, L., Karpova, T.S., and Cooper, J.A. 1994. A yeast actinrelated protein homologous to that in vertebrate dynactin complex is important for spindle orientation and nuclear migration. Cell 78: 669-679.

Pellman, D., Bagget, M., Tu, Y.H., Fink, G.R., and Tu, H. 1995. Two microtubule-associated proteins required for anaphase spindle movement in Saccharomyces cerevisiae. J. Cell Biol. 130: $1373-1385$.

Sagot, I., Klee, S.K., and Pellman, D. 2002. Yeast formins regulate cell polarity by controlling the assembly of actin cables. Nat. Cell Biol. 4: 42-50.

Segal, M. and Bloom, K. 2001. Control of spindle polarity and orientation in Saccharomyces cerevisiae. Trends Cell Biol. 11: $160-166$.

Segal, M., Bloom, K., and Reed, S.I. 2000. Bud6 directs sequential microtubule interactions with the bud tip and bud neck during spindle morphogenesis in Saccharomyces cerevisiae. Mol. Biol. Cell 11: 3689-3702.

Shaw, S.L., Maddox, P., Skibbens, R.V., Yeh, E., Salmon, E.D., and Bloom, K. 1998. Nuclear and spindle dynamics in budding yeast. Mol. Biol. Cell 9: 1627-1631.

Sisson, J.C., Field, C., Ventura, R., Royou, A., and Sullivan, W. 2000. Lava lamp, a novel peripheral Golgi protein, is required for Drosophila melanogaster cellularization. J. Cell Biol. 151: 905-918.

Snyder, M., Gehrung, S., and Page, B.D. 1991. Studies concerning the temporal and genetic control of cell polarity in Saccharomyces cerevisiae. J. Cell Biol. 114: 515-532.

Straight, A.F., Marshall, W.F., Sedat, W.J., and Murray, A.W. 1997. Mitosis in living budding yeast: Anaphase A but no metaphase plate. Science 277: 574-578.

Strome, S. 1993. Determination of cleavage planes. Cell 72: 3-6.

Sullivan, D.S. and Huffaker, T.C. 1992. Astral microtubules are not required for anaphase B in Saccharomyces cerevisiae. I. Cell Biol. 119: 379-388.

Vogel, J. and Snyder, M. 2000. The carboxyl terminus of Tub4p is required for $\gamma$-tubulin function in budding yeast. J. Cell Sci. 21: 3871-3882.

Yeh, E., Skibbens, R.V., Cheng, J.W., Salmon, E.D., and Bloom, K. 1995. Spindle dynamics and cell cycle regulation of dynein in the budding yeast, Saccharomyces cerevisiae. I. Cell Biol. 130: 687-700.

Yeh, E., Yang, C., Chin, E., Maddox, P., Salmon, E.D., Lew, D.J., and Bloom, K. 2000. Dynamic positioning of mitotic spindles in yeast: Role of microtubule motors and cortical determinants. Mol. Biol. Cell 11: 3949-3961.

Yin, H., Pruyne, D., Huffaker, T.C., and Bretscher, A. 2000. Myosin V orientates the mitotic spindle in yeast. Nature 406: $1013-1015$. 


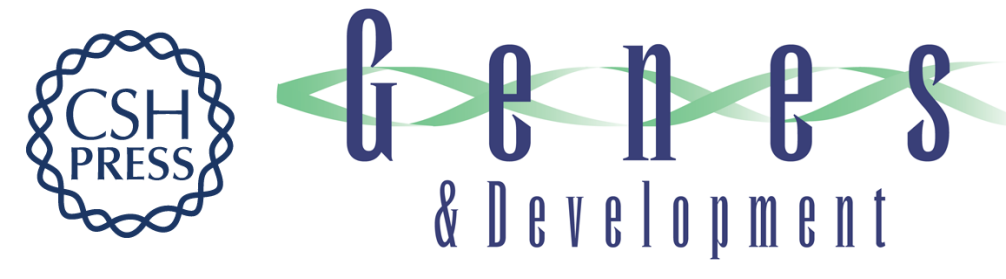

\section{Microtubule capture by the cleavage apparatus is required for proper spindle positioning in yeast}

Justine Kusch, Anne Meyer, Michael P. Snyder, et al.

Genes Dev. 2002, 16:

Access the most recent version at doi:10.1101/gad.222602

References

This article cites 48 articles, 27 of which can be accessed free at: http://genesdev.cshlp.org/content/16/13/1627.full.html\#ref-list-1

License

Email Alerting

Receive free email alerts when new articles cite this article - sign up in the box at the top Service right corner of the article or click here.

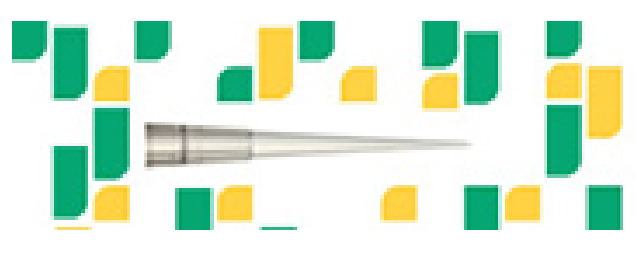

Focused on your science. 